\title{
A Model for Pavement Characteristic Deflection for Rural Roads in Himachal Pradesh
}

\author{
Aakash Gupta, Ashok Kumar Gupta, Ashish Kumar
}

\begin{abstract}
Structural Evaluation of pavements is essential to assess the structural strength of different layers of pavement. It also helps in determining the remaining life of a pavement and the thickness of overlay required. Surface Deflection is the structural response that is easy to measure and hence, commonly used parameter in structural evaluation. In the present study, an attempt has been made to develop a relationship between surface deflection and various structural parameters of pavements selected on low volume flexible rural roads in Himachal Pradesh. Benkelman Beam has been used to determine characteristic deflection on selected 12 rural road stretches in Shimla and Solan district of Himachal Pradesh. Because the conduction of Benkelman Beam Deflection (BBD) test is costly and difficult to carry out in the region of Himachal Pradesh due to hilly and narrow rural roads leading to disruption of traffic, hence, models have been developed to predict surface deflection value using Soaked CBR, Un-soaked CBR, Average Annual Daily Traffic (AADT) and Age of pavement from last overlay (in years). Another model has also been developed to estimate surface deflection using K-value, AADT and age of pavement. Multiple models have been developed using linear regression model. The various developed models have been studied, compared and best model is suggested supporting better coefficient of determination value and root mean square error (RMSE).
\end{abstract}

Keywords: Benkelman Beam, California Bearing Ratio, K-value, AADT, Linear Regression

\section{INTRODUCTION}

$\mathrm{P}$ avements are the main asset of highways which forms the backbone of the economy of any country. The performance of pavements needs to be monitored regularly to meet the service life expectancy corresponding to the intensity of traffic and prevailing environmental conditions. The proper pavement maintenance strategies lead to better economic returns. The pavement performance can be ascertained by functional and structural evaluation of pavements. Structural evaluation can be of two types, Destructive type and Non-Destructive type. In the present study, non-destructive technique has been used to evaluate

Revised Manuscript Received on February 05, 2020.

* Correspondence Author

Aakash Gupta*, Civil Engineering Department, Jaypee University of Information Technology, Solan, India, Email: aakash1991gupta@gmail.com

Ashok Kumar Gupta, Civil Engineering Department, Jaypee University of Information Technology, Solan, India, Email: ashok.gupta@juit.ac.in

Ashish Kumar, Civil Engineering Department, Jaypee University of Information Technology, Solan, India, Email: ashish.fce@juit.ac.in

(C) The Authors. Published by Blue Eyes Intelligence Engineering and Sciences Publication (BEIESP). This is an open access article under the CC BY-NC-ND license (http://creativecommons.org/licenses/by-nc-nd/4.0/) the surface characteristic deflection of selected

flexible rural road stretch using Benkelman Beam.

The study has been conducted on the rural roads of Himachal Pradesh which plays vital role in the development of the state. The total length of rural roads in Himachal Pradesh contributes around $81 \%$ of the total road network in the state. Out of total rural road network, $63 \%$ are tarred roads which need to be maintained timely for their better performance. These roads are not only subjected to heavy traffic loads but also suffer diverse weather of the hills throughout the year leading to heavy wear and tear.

The main objective of the present study is to eradicate the use of costly equipments such as Benkelman Beam, Falling Weight Deflectometer etc. and their cumbersome process of determining surface deflection on narrow and hilly rural roads which leads to disruption of traffic. Hence, attempts have been made to develop a mathematical model which can predict pavement characteristic deflection corresponding to traffic volume, age of pavement (number of years from last overlay), soaked CBR and Un-soaked CBR. Another model has also developed to estimate pavement surface deflection corresponding to traffic volume, age of pavement and K-value. The multiple mathematical models developed have been compared and best model is suggested based on various statistical parameters.

\section{LITERATURE REVIEW}

The pavement deflections were measured by M.S. Hoffman (1983) using Benkelman Beam, Falling weight deflectometer (FWD) and vibratory road rater and various vehicular loadings were used to check the pavement response relevant to structural evaluation on diverse loading conditions. It has been found that Falling Weight Deflectometer simulates the best structural response. It has been found that in major number of pavements, the quasi-loading which is static in nature of BBD induced the highest deflections [1]. Elton and Harr (1988) have devised a new method to measure the deflection of pavement, its profile and texture using a vehicle in motion. A mathematical algorithm has been used to determine the distance and to interpret the deflected and un-deflected profile of pavement. Finally, the deflection is measured by determining the difference between deflected and un-deflected profiles [2]. Y.J. Chou (1993) suggested to use computer based applications instead of performing difficult manual calculations in order to determine characteristic deflections using non-destructive testing on the pavements [3]. S. C. Sharma et al (1996) demonstrated "annual average daily traffic (AADT)" which results from "Short Period Traffic Counts (SPTC)" [4]. 


\section{A Model for Pavement Characteristic Deflection for Rural Roads in Himachal Pradesh}

B. B. Reddy and Veeraragvan (1997) suggested that the characteristic deflection of pavement, rutting and cracking depends largely on the initial starting stage of pavement condition along with the cumulative standard axle loads. Hence, construction quality plays a very important role in pavement performance. It has been concluded that if the two pavements with similar characteristic deflection has been studied after applying a known value of standard axles, then the road section having premix carpet will have more deflection as compared to the road section having asphaltic concrete as its surface course [5]. R.D. McQueen et al (2001) conducted various non-destructive tests on certain road sections of Atlantic City under Federal Aviation Administration which includes FWD "Falling Weight Deflectometer" and HWD "Heavy Falling Weight Deflectometer" testing and documented its response with respect to time [6]. A. K. Abaza (2005) concluded- "flexible pavement overlay design models constructed using performance curve parameters to provide an adequate overlay thickness at any given future time. The undertaken approach attempts to compensate an existing pavement structure for the loss in performance (strength) that it has endured over a specified service time. In essence, this approach is similar to the mechanistic methods of overlay design that make a compensation for the loss in a particular strength indicator such as the commonly used deflection method. Therefore, compensation has been made for the loss in performance as represented by appropriately selected performance curve parameters" [7].

Garg, N., and Hayhoe, G. F. (2008) conducted various non-destructive tests to show that DuPont clay which possess low-strength can be used as subgrade layer and compared with standard subgrade strength [8]. L. Zhou et al (2010) conducted various tests in road sections in China in order to correlate the results obtained from Benkelman Beam deflection and Falling Weight Deflectometer and it has been observed that the modulus obtained from falling weight deflectometer can be used in further study [9]. Joseph, D., and Vipulanandan, C. (2011) utilized finite element method for modelling the CBR values for the tests conducted on two soil samples [10]. A.K. Khaweir (2011) determined the parameters which affects mostly during the process of overlay design and it has been found that traffic load and layer thickness plays a vital role in this regard [11]. R. Nayak et al (2012) implemented a data acquisition system which would help in road asset management and assessing the performance of road [12].

\section{METHODOLOGY}

In the present study, data collection has been done on selected 12 flexible rural road stretches in the vicinity of Shimla and Solan district of Himachal Pradesh each of 2.5 $\mathrm{km}$ with an average width of 3 metre as given in Table 1 . The selected rural roads are directly connected to the National Highway No. 5 and the maps of selected road stretches are given in Fig. 1 and Fig. 2. The $2.5 \mathrm{~km}$ stretches [16] were chosen in such a way that the selected section represents the whole stretch of the road in respect of traffic volume, climatic conditions etc.

Table 1. Selected Rural Road Stretches

\begin{tabular}{|c|c|c|c|}
\hline $\begin{array}{c}\text { Road } \\
\text { ID }\end{array}$ & Road Name & $\begin{array}{c}\text { Road } \\
\text { ID }\end{array}$ & Road Name \\
\hline
\end{tabular}

\begin{tabular}{|c|c|c|c|}
\hline RR-1 & Domehar-Waknaghat Road & RR-7 & Shoghi-Heon Road \\
\hline RR-2 & Salogra-Ashwini Khad Road & $\mathbf{R R - 8}$ & Shoghi-JaogRoad \\
\hline RR-3 & $\begin{array}{c}\text { Kyari Bangla-Dera Road } \\
\text { RR-9 }\end{array}$ & $\begin{array}{c}\text { Kandaghat-Kot } \\
\text { Road }\end{array}$ \\
\hline RR-4 & Basha Road & RR-10 & Chail Road \\
\hline RR-5 & $\begin{array}{c}\text { Khawara Chowki-Mashru } \\
\text { Road }\end{array}$ & RR-11 & Nain Basal Road \\
\hline RR-6 & Shoghi-Dooh Road & RR-12 & Solan-Malaun Road \\
\hline
\end{tabular}

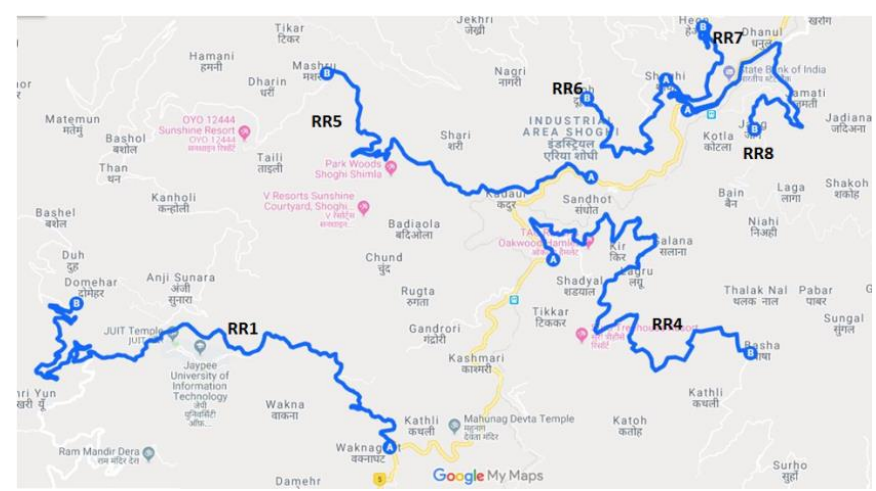

Fig. 1. Map of Selected Rural Road Stretches

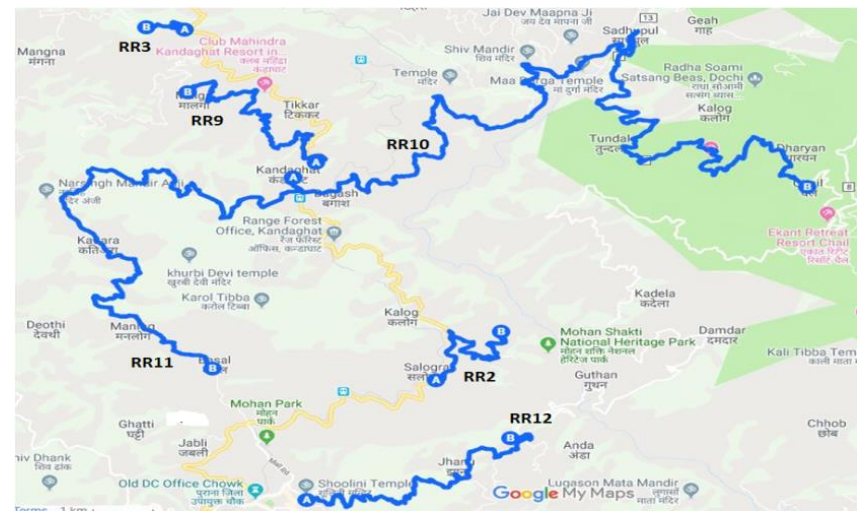

Fig. 2. Map of Selected Rural Road Stretches

Non-Destructive Benkelman Beam Deflection study was conducted on the selected sections using Benkelman Beam as shown in Fig. 3. It was decided that 10 measurement points per kilometre will be taken for data collection. Hence, 25 points per road stretch were selected to determine the characteristic deflection as per the procedure laid down in IRC: 81-1997 "Guidelines for strengthening of flexible road pavements using Benkelman Beam Deflection Technique" [13]. A standard two axle truck having rear axle load of 8.16 tonnes and tyre pressure of $5.6 \mathrm{~kg} / \mathrm{cm}^{2}$ was used for measurement of initial reading, intermediate reading and final reading at each selected point $60 \mathrm{~cm}$ away from the pavement edge. The temperature correction was not applied because the average day temperature in the selected stretch region is less than $20^{\circ} \mathrm{C}$ for more than four months in a year. All the deflection measurements have been made when the ambient temperature was greater than $20^{\circ}$ as suggested by IRC: 81-1997 [13]. 
Subgrade soil samples were taken from the test pits evaluation for determining the subgrade moisture content. These soil samples were oven dried in the laboratory for finding out the moisture content needed for applying moisture correction factor in characteristic deflection calculations. The surface characteristic deflection of all the selected 12 rural roads after applying required corrections is shown in Fig. 4.

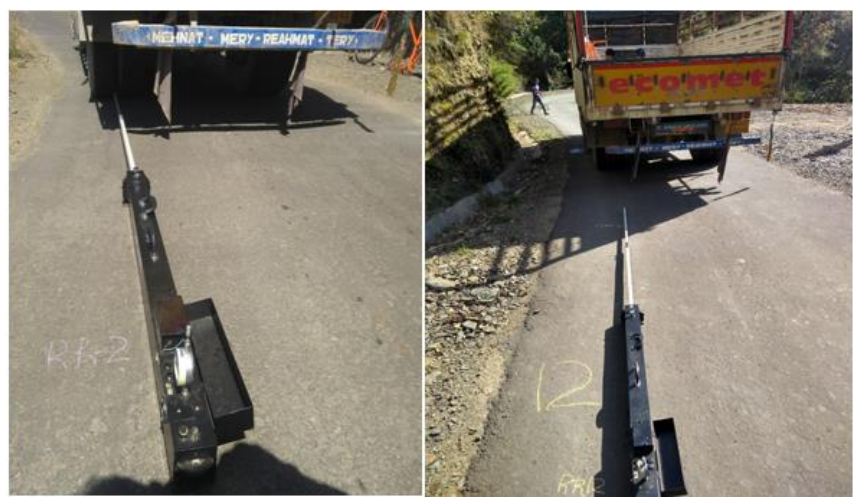

Fig. 3. Benkelman Beam Deflection study on selected stretches

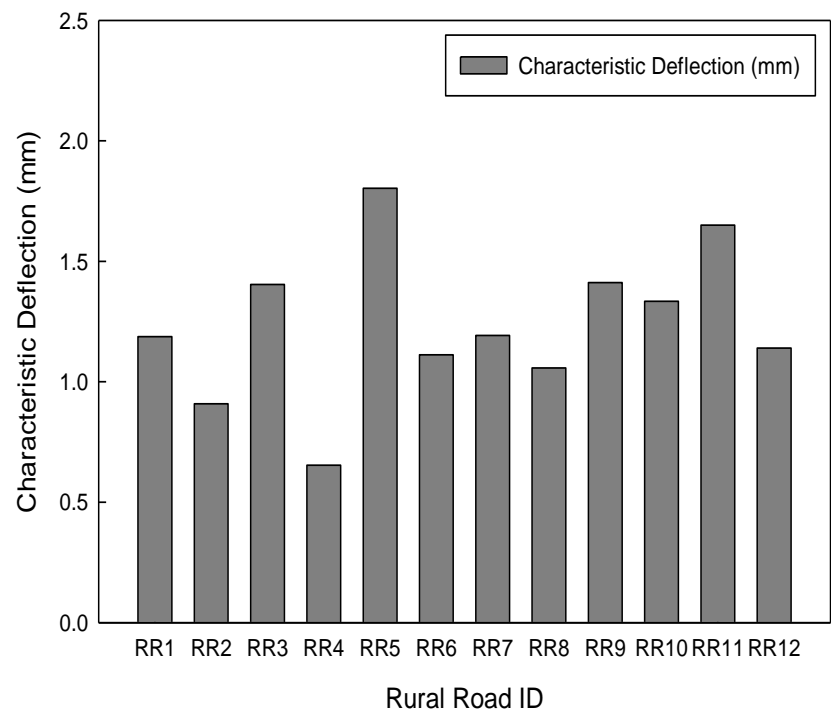

Fig. 4. Characteristic Deflection of all selected stretches

California Bearing Ratio (CBR) Test has been conducted on disturbed subgrade soil samples taken from selected 12 rural road stretches. Three subgrade soil samples were taken from each selected road stretch. All soil samples were tested in laboratory (Fig. 5) to determine the Soaked CBR value and Unsoaked CBR value. The average value of the three soil samples has been taken as shown in Table 2. The final average soaked CBR value and unsoaked CBR value of all the selected 12 rural road stretches has been shown in Fig. 6. The modulus of subgrade reaction (K-value) has also been determined approximately corresponding to the soaked CBR value using IRC: 58-2002 "Guidelines for the design of plain jointed Rigid Pavements for highways" [14] as shown in Table 3.

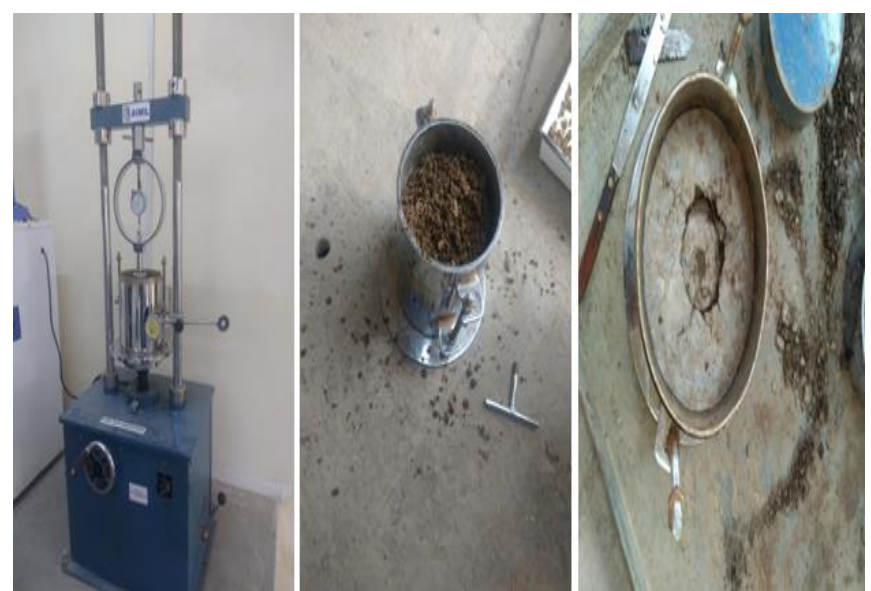

Fig. 5. California Bearing Ratio Test in Laboratory

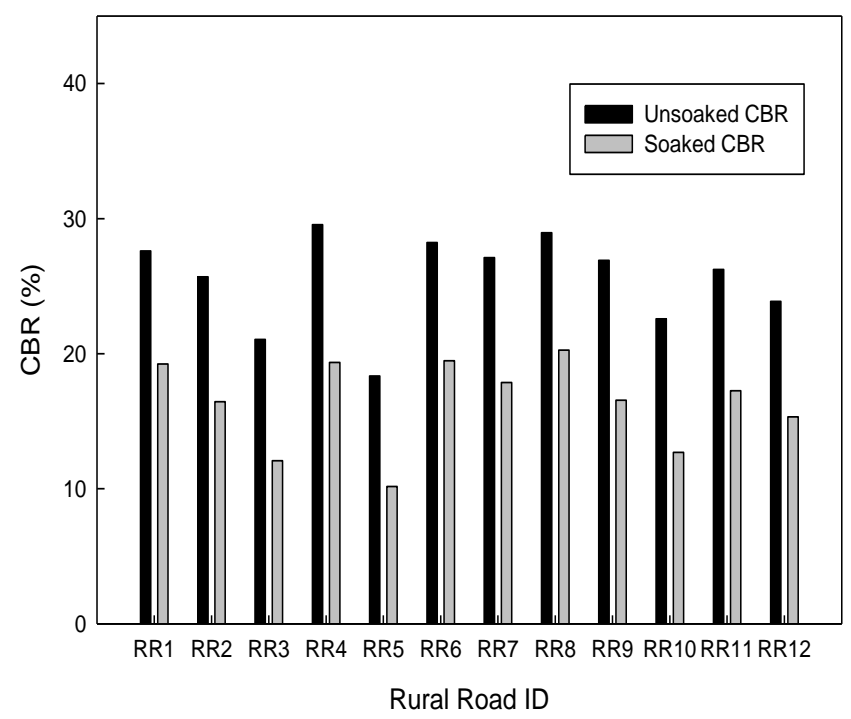

Fig. 6. Unsoaked CBR and Soaked CBR Values of selected stretches

Classified traffic volume surveys were conducted manually for 72 hours round the clock, by employing skilled enumerators, covering all types of vehicles viz: Buses, two-axle Trucks, multi-axle trucks, light commercial vehicles, light passenger vehicles and Two-wheelers. The traffic volume survey was done twice i.e. in lean season and in peak season, both for 72 hours as shown in Fig. 7 and Fig. 8. The traffic volume has been presented in Average Annual Daily Traffic (AADT) on all the selected rural road stretches using IRC: SP: 72-2015 "Guidelines for the design of Flexible Pavements for Low Volume Rural Roads" [15] as shown in Fig. 9.

The age of pavement i.e. the number of years from last overlay till the year in which the Benkelman Beam study conducted was taken from DPR of the selected road sections available with PWD, Himachal Pradesh and shown in Table 4.

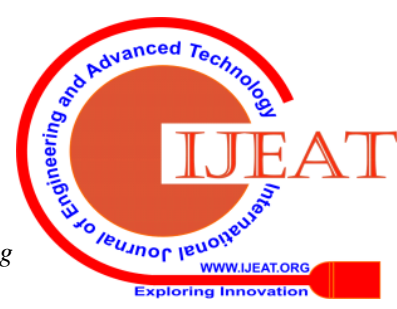


A Model for Pavement Characteristic Deflection for Rural Roads in Himachal Pradesh

Table 2. Unsoaked CBR and Soaked CBR Values of all soil samples

\begin{tabular}{|l|r|r|r|r|r|r|r|r|}
\hline & \multicolumn{3}{|c|}{ Unsoaked CBR } & \multicolumn{4}{|c|}{ Soaked CBR } \\
\hline Roads & CBR-1 & \multicolumn{1}{|c|}{ CBR-2 } & \multicolumn{1}{c|}{ CBR-3 } & $\begin{array}{c}\text { Average } \\
\text { CBR (\%) }\end{array}$ & \multicolumn{1}{c|}{ CBR-1 } & CBR-2 & CBR-3 & $\begin{array}{c}\text { Average } \\
\text { CBR (\%) }\end{array}$ \\
\hline RR1 & 26.58 & 28.32 & 27.93 & 27.61 & 18.54 & 19.01 & 20.14 & 19.23 \\
\hline RR2 & 24.54 & 25.01 & 27.52 & 25.69 & 15.24 & 15.97 & 18.11 & 16.44 \\
\hline RR3 & 19.89 & 22.41 & 20.85 & 21.05 & 10.22 & 11.58 & 14.41 & 12.07 \\
\hline RR4 & 28.69 & 29.11 & 30.85 & 29.55 & 18.64 & 19.41 & 20 & 19.35 \\
\hline RR5 & 17.68 & 19.21 & 18.16 & 18.35 & 9.73 & 11.52 & 9.26 & 10.17 \\
\hline RR6 & 27.85 & 26.35 & 30.49 & 28.23 & 18.26 & 19.71 & 20.47 & 19.48 \\
\hline RR7 & 26.25 & 28.95 & 26.13 & 27.11 & 15.65 & 16.87 & 21.06 & 17.86 \\
\hline RR8 & 27.36 & 28.34 & 31.15 & 28.95 & 19.22 & 20.35 & 21.21 & 20.26 \\
\hline RR9 & 25.06 & 27.47 & 28.2 & 26.91 & 15.74 & 16.46 & 17.45 & 16.55 \\
\hline RR10 & 19.27 & 23.18 & 25.29 & 22.58 & 11.84 & 12.12 & 14.11 & 12.69 \\
\hline RR11 & 25.88 & 26.41 & 26.43 & 26.24 & 15.98 & 16.48 & 19.32 & 17.26 \\
\hline RR12 & 22.91 & 24.75 & 23.95 & 23.87 & 14.21 & 15.49 & 16.29 & 15.33 \\
\hline
\end{tabular}

Table 3. K-value of all selected stretches

\begin{tabular}{|l|c|c|c|c|c|c|c|c|c|c|c|c|}
\hline Road ID & RR1 & RR2 & RR3 & RR4 & RR5 & RR6 & RR7 & RR8 & RR9 & RR10 & RR11 & RR12 \\
\hline K-Value & 6.79 & 6.40 & 5.79 & 6.81 & 5.52 & 6.83 & 6.60 & 6.96 & 6.42 & 5.88 & 6.52 & 6.25 \\
\hline
\end{tabular}

Table 4. Age of Pavement from last overlay (in years) of all selected stretches

\begin{tabular}{|c|c|c|c|c|c|c|c|c|c|c|c|c|}
\hline Road ID & RR1 & RR2 & RR3 & RR4 & RR5 & RR6 & RR7 & RR8 & RR9 & RR10 & RR11 & RR12 \\
\hline Age (years) & 7 & 5 & 7 & 6 & 6 & 7 & 5 & 6 & 7 & 7 & 6 & 7 \\
\hline
\end{tabular}

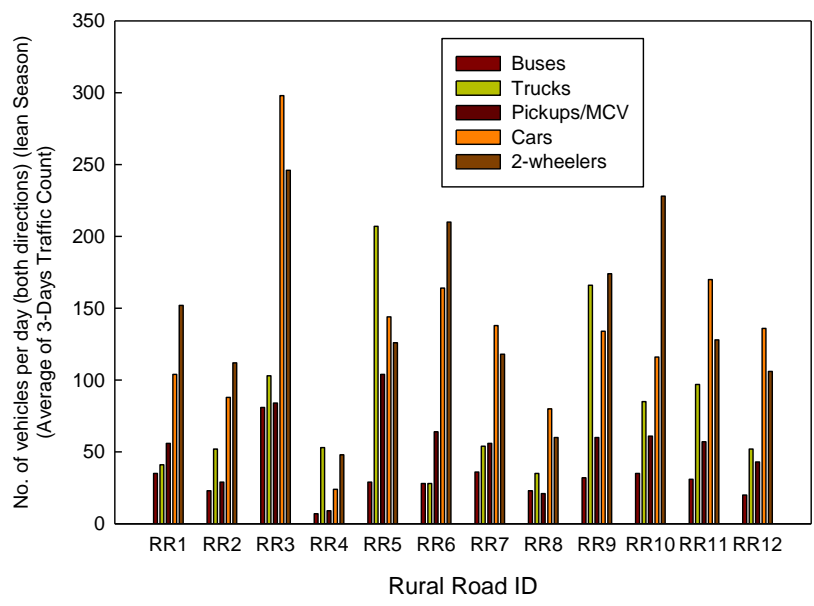

Fig. 7. Traffic Volume Survey for Lean Season

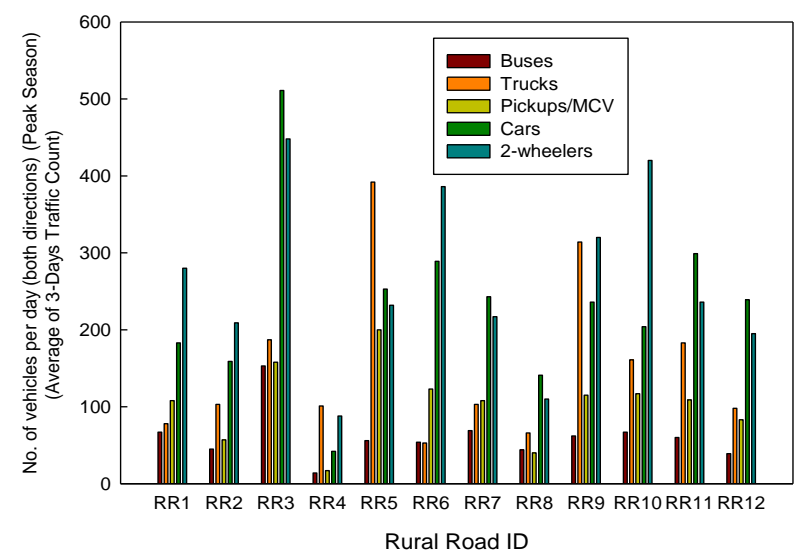

Fig. 8. Traffic Volume Survey for Peak Season 


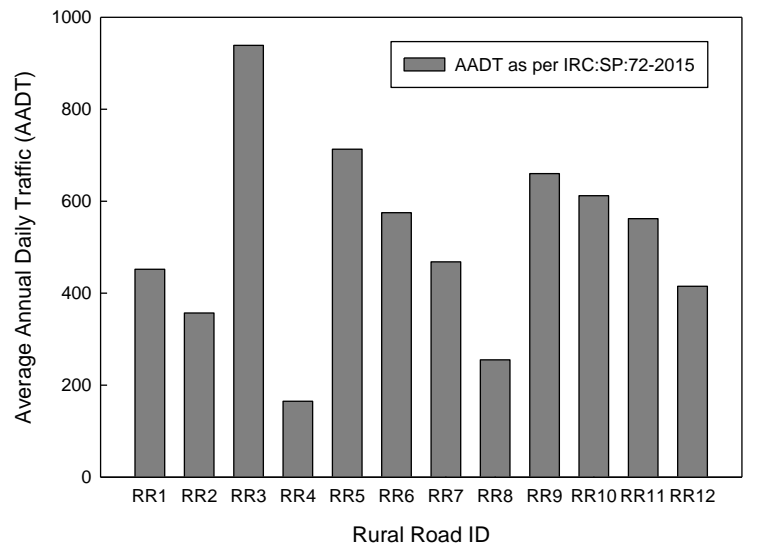

Fig. 9. Average Annual Daily Traffic of selected stretches

\section{MODEL DEVELOPMENT}

Attempts has been made to develop a mathematical model to predict the characteristic pavement deflection based on Soaked CBR value, Un-soaked CBR value, Average Annual Daily Traffic (AADT) and Age of pavement from last overlay (in years). Another model has also been developed to estimate surface deflection using K-value, Average Annual Daily Traffic (AADT) and age of pavement (in years). Multiple models have been developed using linear regression model in PYTHON. The various developed models have been studied, compared and best model is suggested based on various statistical parameters such as Mean Absolute Error (MAE), Mean Squared Error (MSE), Root Mean Squared Error (RMSE) and $\mathrm{R}^{2}$ value.

Two models have been developed using linear regression with sklearn library of PYTHON. All the parameters have been plotted as shown in Fig. 10 and Fig. 11 to check the correlation in between the parameters. The correlation matrix has been developed as shown in Table 5 and Table 6 which shows that soaked CBR and unsoaked CBR are highly correlated to each other and hence unsoaked CBR parameter has been removed to develop the final mathematical model. The following two mathematical models (Eq. 1 \& Eq. 2) has been suggested and various statistical parameters of the models have been determined using sklearn library tools of PYTHON-

$$
\begin{gathered}
D_{c}=0.755147+0.001561 * A A D T-0.025788 * \text { Age }- \\
0.00681 * S \_C B R \quad(\text { Eq. } 1) \\
\mathrm{MAE}=0.17, \mathrm{MSE}=0.06 \\
\mathrm{RMSE}=0.19, \mathrm{R}^{2}=0.76 \\
D_{c}=0.848226+0.001568 * A A D T-0.026334 * \text { Age }- \\
0.032537 * \text { K-value } \quad(\mathrm{Eq} .2) \\
\mathrm{MAE}=0.18, \mathrm{MSE}=0.07 \\
\mathrm{RMSE}=0.21, \mathrm{R}^{2}=0.72
\end{gathered}
$$

Where,

$$
\begin{aligned}
& \mathrm{D}_{\mathrm{c}}=\text { Pavement Characteristic Deflection }(\mathrm{mm}) \\
& \text { AADT }=\text { Average Annual Daily Traffic } \\
& \text { Age }=\text { Age of pavement from last overlay (in Years) } \\
& \text { S_CBR }=\text { Soaked CBR value }(\%) \\
& \text { K-value }=\text { Modulus of subgrade reaction }\left(\mathrm{kg} / \mathrm{cm}^{3}\right) \\
& \text { MAE }=\text { Mean Absolute Error } \\
& \text { MSE }=\text { Mean Squared Error } \\
& \text { RMSE }=\text { Root Mean Squared Error }
\end{aligned}
$$

\section{RESULTS}

The Benkelman beam study conducted on all the twelve selected rural road stretches shows that RR5 has the most characteristic deflection value of $1.8 \mathrm{~mm}$ and RR4 has the least deflection value of $0.65 \mathrm{~mm}$ (Fig. 4). Hence RR5 needs to be maintained first out of the twelve selected stretches. The average unsoaked CBR value of RR5 is $18.35 \%$ (Table. 2) which is least among all the selected roads which show poor subgrade strength. The average annual daily traffic (AADT) of 940 is maximum on RR3 followed by RR5 with an AADT of 713 (Fig. 9), hence the traffic volume on RR5 has significant contribution to the pavement deflection value of $1.8 \mathrm{~mm}$. The age of pavement from last overlay is in the range of 5-7 years. The two mathematical models developed are evaluated using statistical parameters such as Mean Absolute Error (MAE), Mean Squared Error (MSE) and Root Mean Squared Error (RMSE) as shown in Eq. 1 and Eq. 2. The model developed in Eq. 1 is found to be better than model developed in Eq. 2 depending upon better RMSE value of 0.19 as compared to 0.21 of Eq. 2 . The $\mathrm{R}^{2}$ value of Eq. 1 is 0.76 which shows a good fit as compared to 0.72 of Eq. 2 .

\section{CONCLUSIONS}

The structural evaluation data collected on the selected twelve rural road stretches in Shimla and Solan district of Himachal Pradesh are used in the present study to develop mathematical models to predict Benkelman beam characteristic deflection based on Soaked CBR, Un-soaked CBR, Average Annual Daily Traffic (AADT), Age of pavement from last overlay (in years) and K-value. The models have been developed using linear regression analysis with the help of sklearn library in PYTHON. The correlation matrix has been formed to check the correlation within the parameters. Soaked CBR and Unsoaked CBR are found to be highly correlated to each other and hence either of these may be neglected. In the present study, unsoaked CBR has been neglected in the modelling as soaked CBR being good representative of structural strength of pavement subgrade. The developed models have been compared based on conventional statistical parameters such as MAE, MSE, RMSE and $\mathrm{R}^{2}$ values. It has been found that the model developed to predict pavement deflection using soaked CBR, AADT and age of pavement is found to be more accurate as $\mathrm{R}^{2}$ value of 0.76 and RMSE value of 0.19 being good as compared to other model.

Modelling of characteristic deflection is very essential for the pavement maintenance management system and structural analysis of pavements. Prediction of characteristic deflection value using mathematical models can give easy estimates of overlay design without carrying out actual Benkelman beam survey in the field which leads to disruption of traffic on narrow rural roads of Himachal Pradesh and increase in cost of the project. The present study uses five structural parameters for predicting the pavement characteristic deflection. Future study may include some more structural parameters and more stretches may be selected of longer length in kilometres to further improve the present developed models. 
A Model for Pavement Characteristic Deflection for Rural Roads in Himachal Pradesh
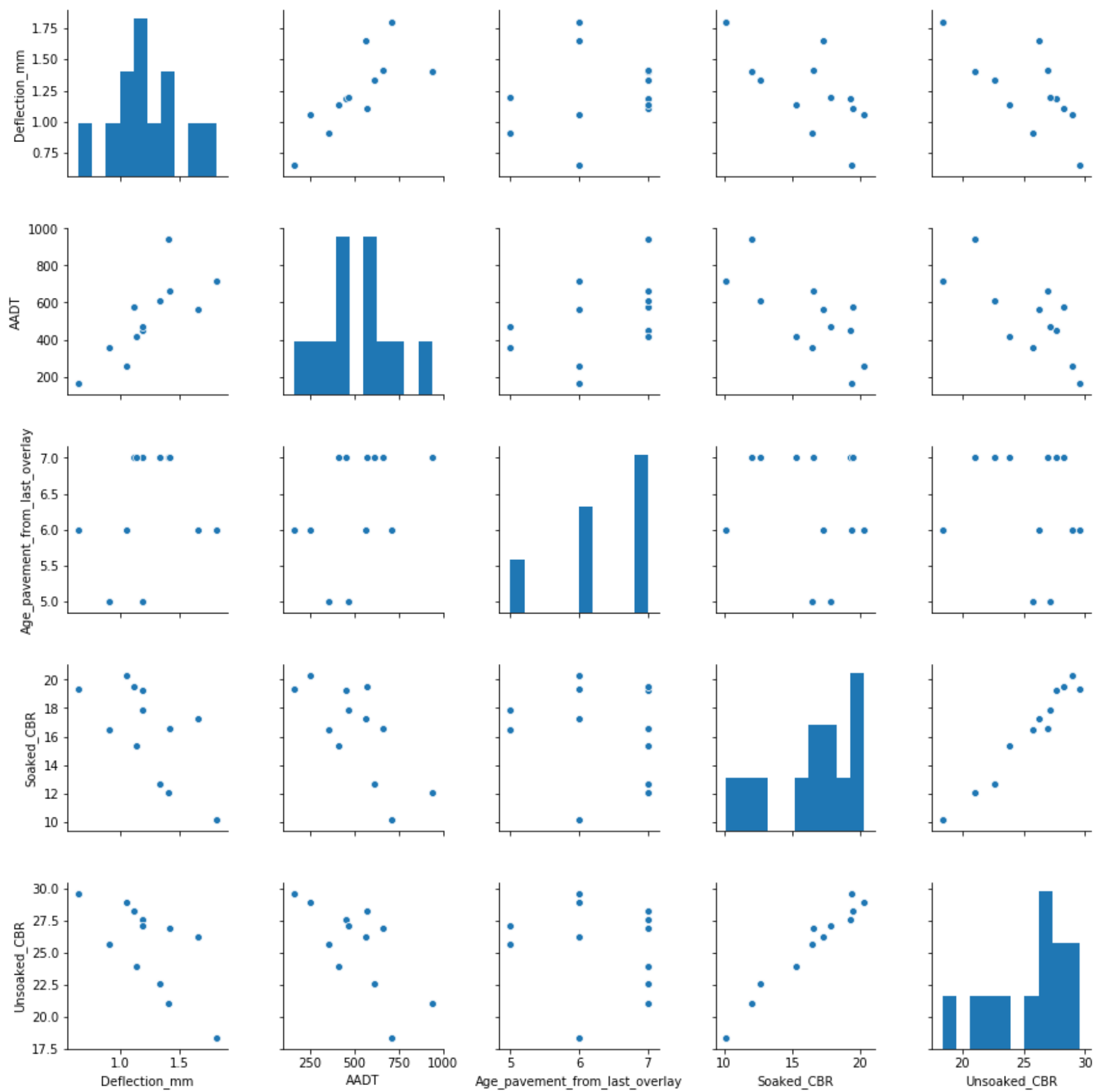

Fig. 10. Correlation between the parameters

Table 5. Correleation Matrix

\begin{tabular}{|l|l|l|l|l|l|}
\hline & Deflection_mm & AADT & Age_pavement_from_last_overlay & Soaked_CBR & Unsoaked_CBR \\
\hline Deflection_mm & & 0.75917 & 0.20099 & -0.640273 & -0.679112 \\
\hline AADT & 0.75917 & 1 & 0.427974 & -0.712567 & -0.707421 \\
\hline Age_pavement_from_last_overlay & 0.20099 & 0.427974 & & -0.161976 & -0.157676 \\
\hline Soaked_CBR & -0.640273 & -0.712567 & -0.161976 & 1 & 0.978619 \\
\hline Unsoaked_CBR & -0.679112 & -0.707421 & -0.157676 & 0.978619 & 1 \\
\hline
\end{tabular}

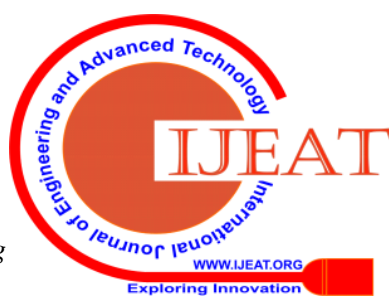



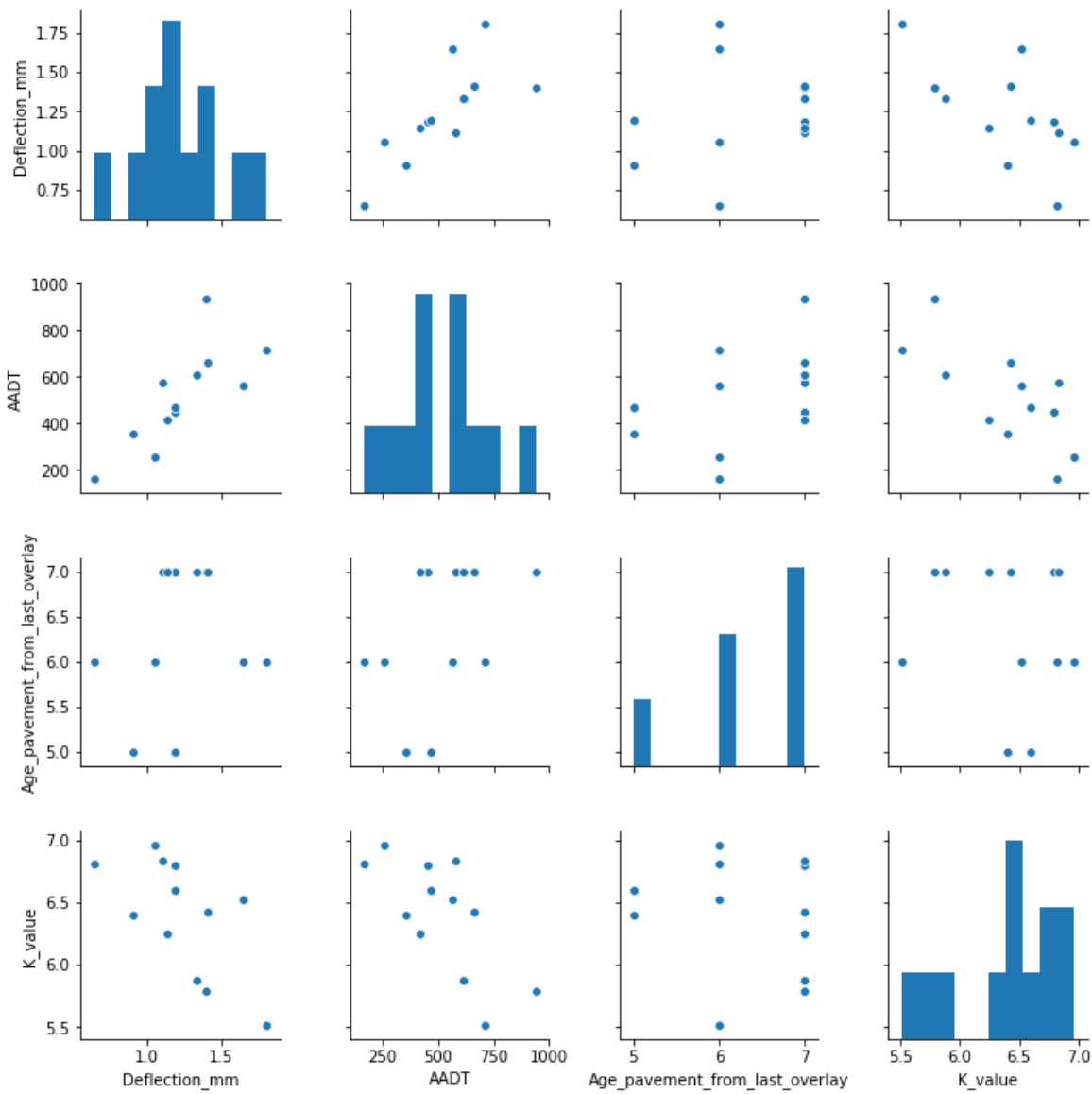

Fig. 11. Correlation between the parameters

Table 6. Correleation Matrix

\begin{tabular}{|l|l|l|l|l|}
\hline & Deflection_mm & AADT & Age_pavement_from_last_overlay & K_value \\
\hline Deflection_mm & & 0.75917 & 0.20099 & -0.639065 \\
\hline AADT & 0.75917 & 1 & 0.427974 & -0.713565 \\
\hline Age_pavement_from_last_overlay & 0.20099 & 0.427974 & 1 & -0.160441 \\
\hline K_value & -0.639065 & -0.713565 & -0.160441 & 1 \\
\hline
\end{tabular}

\section{REFERENCES}

1. Hoffman, M. S. (1983). Loading mode effects on pavement deflections. Journal of transportation engineering, 109(5), 651-668.

2. Elton, D. J., and Harr, M. E. (1988). New nondestructive pavement evaluation method. Journal of transportation engineering, 114(1), 76-92.

3. Chou, Y. J. (1993). Knowledge-based system for flexible pavement structural evaluation. Journal of transportation engineering, 119(3), 450-466.

4. Sharma, S. C., Gulati, B. M., and Rizak, S. N. (1996). Statewide traffic volume studies and precision of AADT estimates. Journal of transportation engineering, 122(6), 430-439.

5. Reddy, B. B., and Veeraragavan, A. (1997). Structural performance of inservice flexible pavements. Journal of transportation engineering, 123(2), 156-167.

6. McQueen, R. D., Marsey, W., and Arze, J. M. (2001). Analysis of nondestructive test data on flexible pavements acquired at the National Airport Pavement Test Facility. In Advancing Airfield Pavements (pp. 267-278).

7. Abaza, K. A. (2005). Performance-based models for flexible pavement structural overlay design. Journal of Transportation Engineering, 131(2), 149-159.

8. Garg, N., and Hayhoe, G. F. (2008). Performance of Flexible Pavements over Two Subgrades with Similar CBR but Different Soil Types (Silty Clay and Clay) at the FAA's National Airport Pavement Test Facility. In Airfield and Highway Pavements: Efficient Pavements Supporting Transportation's Future (pp. 487-496).
9. Zhou, L., Wu, Q., and Ling, J. (2010). Comparison of FWD and Benkelman beam in evaluation of pavement structure capacity. In Paving Materials and Pavement Analysis (pp. 405-411).

10. Joseph, D., and Vipulanandan, C. (2011). Characterization of Field Compacted Soils (Unsoaked) Using the California Bearing Ratio (CBR) Test. In Geo-Frontiers 2011: Advances in Geotechnical Engineering (pp. 2719-2728).

11. Khweir, K. A. (2011). United Kingdom overlay design of flexible pavement: determination of the important parameters. Journal of Transportation Engineering, 138(3), 324-331.

12. Nayak, R., Rawat, R., and Weligamage, J. (2012, December). A data analytics application assessing pavement deflection factors for a road network. In Proceedings of the 14th International Conference on Information Integration and Web-based Applications \& Services (pp. 247-255). ACM.

13. IRC: 81-1997, Guidelines for strengthening of flexible road pavements using Benkelman Beam Deflection Technique.

14. IRC: 58-2002, Guidelines for the design of plain jointed Rigid Pavements for highways

15. IRC: SP: 72-2015, Guidelines for the design of Flexible Pavements for Low Volume Rural Roads.

16. Gupta, A., Gupta, A.K., and Kumar, A. (2019). Development of Maintenance Management System by Functional Evaluation for Rural Roads in Himachal Pradesh, International Journal of Recent Technology and Engineering (IJRTE) ISSN: 2277-3878, Volume-8, Issue-1, May 2019 